University of Nebraska - Lincoln

DigitalCommons@University of Nebraska - Lincoln

\title{
Electrodeposition and Magnetic Properties of Polypyrrole-Fe Nanocomposites
}

\author{
Mircea Chipara \\ University of Texas-Pan American, mchipara@utpa.edu \\ Ralph Skomski \\ University of Nebraska at Lincoln, rskomski2@unl.edu \\ David J. Sellmyer \\ University of Nebraska-Lincoln, dsellmyer@unl.edu
}

Follow this and additional works at: https://digitalcommons.unl.edu/physicssellmyer

Part of the Physics Commons

Chipara, Mircea; Skomski, Ralph; and Sellmyer, David J., "Electrodeposition and Magnetic Properties of Polypyrrole-Fe Nanocomposites" (2007). David Sellmyer Publications. 211.

https://digitalcommons.unl.edu/physicssellmyer/211

This Article is brought to you for free and open access by the Research Papers in Physics and Astronomy at DigitalCommons@University of Nebraska - Lincoln. It has been accepted for inclusion in David Sellmyer Publications by an authorized administrator of DigitalCommons@University of Nebraska - Lincoln. 
Published in Materials Letters 61:11-12 (May 2007), pp. 2412-2415;

doi 10.1016/j.matlet.2006.09.024 Copyright (C) 2006 Elsevier B.V. Used by permission.

http://www.elsevier.com/wps/product/cws_home/505672

Submitted January 30, 2006; accepted September 13, 2006; published online October 2, 2006.

\title{
Electrodeposition and magnetic properties of polypyrrole-Fe nanocomposites
}

\author{
Mircea Chipara, ${ }^{*}$ Ralph Skomski, ${ }^{\dagger}$ and David J. Sellmyer ${ }^{\dagger}$ \\ * Department of Physics and Geology, University of Texas-Pan American, Edinburg, TX, USA \\ † Department of Physics and Astronomy, University of Nebraska-Lincoln, Lincoln, NE 68588, USA \\ Corresponding author - M. Chipara, Department of Physics and Geology, 1201 W. University Drive, \\ Edinburg, TX 78541-2999, USA; tel 956 381-3521, fax 956 381-2423, email mchipara@utpa.edu
}

\begin{abstract}
The synthesis, structure, and magnetic properties of a new composite material obtained by the codeposition of polypyrrole and iron, in the galvanostatic mode, using square wave potentials are reported. The effect of electrodeposition conditions (voltage and concentration of the electrolytes) on the magnetic properties of the nanocomposite is analyzed.
\end{abstract}

Keywords: nanocomposites, electrodeposition, x-ray diffraction, polypyrrole, iron, coercivity

\section{Introduction}

Composite materials based on magnetic and/or conducting materials exhibit new or enhanced physical properties, of interest for future applications [1-6]. Polypropylene-graphite composites showed [2] a positive transverse magnetoresistance (larger than 10\%) above the percolation threshold. Magnetoresistance of about $10 \%$ (in $1.0 \mathrm{~T}$, with an applied voltage of $100 \mathrm{~V}$ ) was reported [5] in polyvinyl alcohol- $\mathrm{Fe}_{3} \mathrm{O}_{4}$ [5]. The doping of poly3-dodecylthiophene (conducting polymer) with $\mathrm{FeCl}_{3}$ resulted in unusual diamagnetic properties [4], which suggested the presence of small superconducting regions at room temperature. Nanocomposites of conducting polymers (polypyrrole-PPY) and magnetite were chemically prepared [6]. The magnetic nanoparticles (with an average size ranging from 14 to $90 \mathrm{~nm}$ ) were characterized [6] by superparamagnetic to weak ferromagnetic properties (magnetization at saturation of $43.7 \mathrm{emu} / \mathrm{g}$ and coercive fields ranging from 9 to $57 \mathrm{Oe}$ ). Nanocomposites that combine both charge transport and magnetic properties are expected to present applications in spintronics.

The PPY-Fe composites combine the electrical features of polypyrrole [7] with the magnetic properties of Fe. Polypyrrole shows a plasma resonance in microwaves [11] while Fe exhibits a ferromagnetic resonance in the same frequencies domain, in magnetic fields of about 3500 Gs. Such composite is an ideal candidate for magnetically tuned negative index of refraction materials [18].

\section{Experimental methods}

Fe-PPY composites have been obtained by codeposition, in the galvanostatic mode using square wave potentials (see Figure 1A), at room temperature and under nitrogen atmosphere. Pristine and doped Fe-PPY were obtained in aqueous solutions containing $0.1 \mathrm{M}$ pyrrole, $0.2 \mathrm{M}$ oxalic acid, $0.1 \mathrm{M} \mathrm{LiClO}_{4}$, and $2 \mathrm{M} \mathrm{FeSO}_{4}$. The following raw materials have been used to obtain pristine and doped Fe-PPY composites: pyrrole, reagent grade98\% purity from Sigma (131709), oxalic acid, purity better than 99\% from Sigma (241172), anhydrous lithium perchlorate from Aesar (L15713), iron sulfate hydrate, purity $99.999 \%$ from Sigma, (450278) silver foils with a thickness of $0.05 \mathrm{~mm}$ and purity $99.95 \%$ from Goodfellow, and double distilled deionized water. Asymmetric square wave potentials (amplitudes of $-0.5 \mathrm{~V}$ to $-1.5 \mathrm{~V}$ 

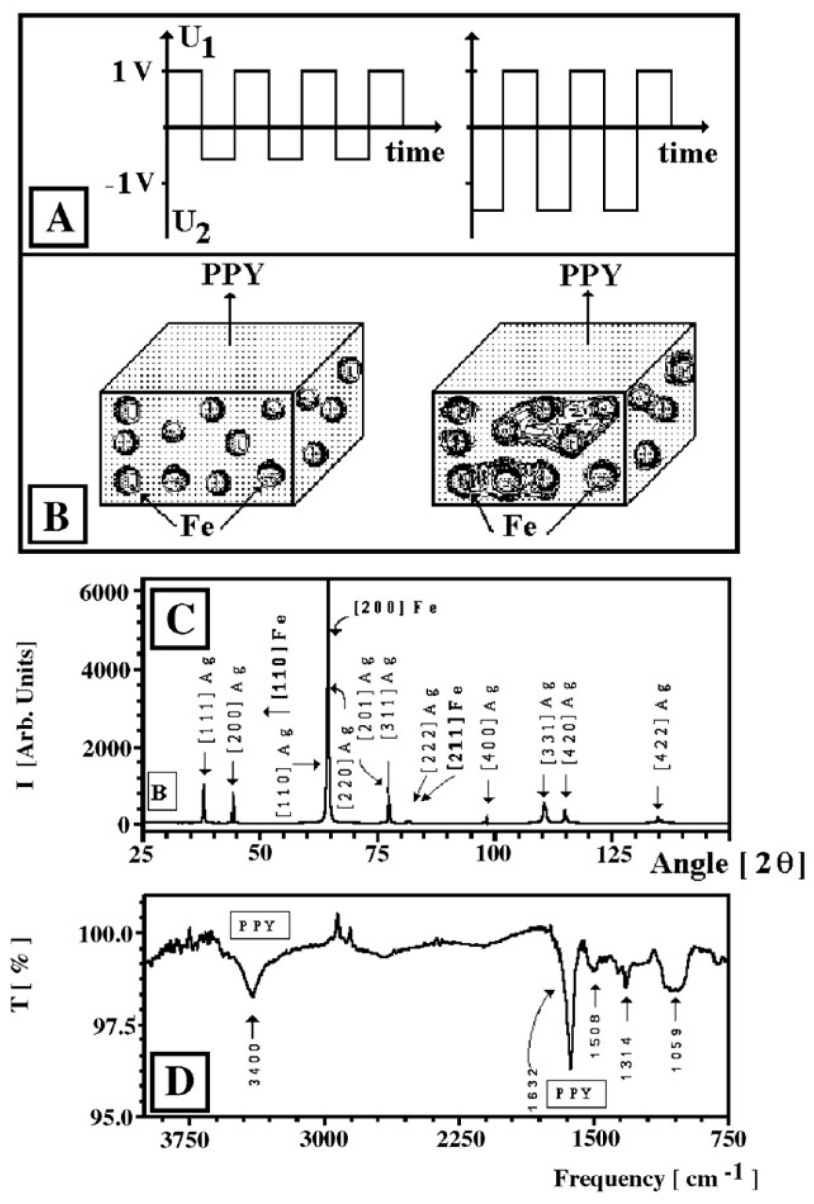

Figure 1. A. Electrodeposition process. B. Structure of PPYFe: short electrodeposition time or/and low $U_{2}$ (left) and large electrodeposition time and/or $U_{2}$ (right). C. WAXS spectrum of PPY-Fe nanocomposites. D. FTIR spectrum of PPY-Fe nanocomposites.

for iron electrodeposition and $+1.0 \mathrm{~V}$ for PPY deposition, measured relative to a calomel reference electrode with widths of $0.1 \mathrm{~s}$ ) were applied to codeposit both PPY and Fe on thin silver foils, using an EG\&G Princeton Applied Research Model 273A potentiostat/galvanostat. The polymer was deposited during the positive pulse while the metal was deposited during the negative pulse. The samples have been analyzed by Fourier Transform Infra Red (FTIR) spectroscopy, Wide Angle X-ray Spectroscopy (WAXS), Alternating Gradient Force Magnetometry (AGFM), and Transmission Electron Microscopy (TEM).

\section{Results and discussion}

The presence of PPY was confirmed by FTIR spectra (reflection mode; see Figure 1C). The broad line located at $3400 \mathrm{~cm}^{-1}$ is typical for pristine and doped polypyrrole [9]. A strong band located around $3400 \mathrm{~cm}^{-1}$ was reported in perchlorate $\left(\mathrm{ClO}^{4-}\right)$ doped polypyrrole [10]. However, in the case of electrodeposited polypyrroles (such as polypyrrole doped with tetraborofluorate $\left(\mathrm{BF}_{4}^{-}\right)$and toluene sulfonate $\left.\left(\mathrm{TSO}^{-}\right)\right)$, this band was not observed. For heavily doped polypyrrole, a complex band structure was noticed for wavelength ranging from 1700 to $1000 \mathrm{~cm}^{-1}$ [11]. The strongest band is located at $1640 \mathrm{~cm}^{-1}$ and represents complex out of the plane vibrations [9]. It was suggested [8] that the band located at $1642 \mathrm{~cm}^{-1}$ originates from amine vibrations within the pyrrole ring. As this band is broad, both contributions may be present. Between $1100 \mathrm{~cm}^{-1}$ and $980 \mathrm{~cm}^{-1}$, a broad band centered on $1060 \mathrm{~cm}^{-1}$ has been recorded (see Figure 1C). This band may represent the convolution of several narrower bands (the experimental band observed in polypyrrole at $960 \mathrm{~cm}^{-1}$, a band due to complex out of plane vibrations located at $1040 \mathrm{~cm}^{-1}$, and a band located at $1060 \mathrm{~cm}^{-1}$ due to $\mathrm{C}-\mathrm{H}$ in-plane bending and ring deformations). The weak band located close to $750 \mathrm{~cm}^{-1}$ is assigned to the out of plane deformation of the $\mathrm{C}-\mathrm{H}$ bond, in bulk polypyrrole [12]. The absence of the lines located at $920 \mathrm{~cm}^{-1}$, and $3100 \mathrm{~cm}^{-1}$ (OH stretch) suggests that iron hydroxides are not present in the as deposited nanocomposite [13].

The WAXS spectrum of PPY-Fe composite deposited on silver is shown in the Figure 1B. The lines due to cubic or hexagonal silver substrate dominate the spectrum. The most intense
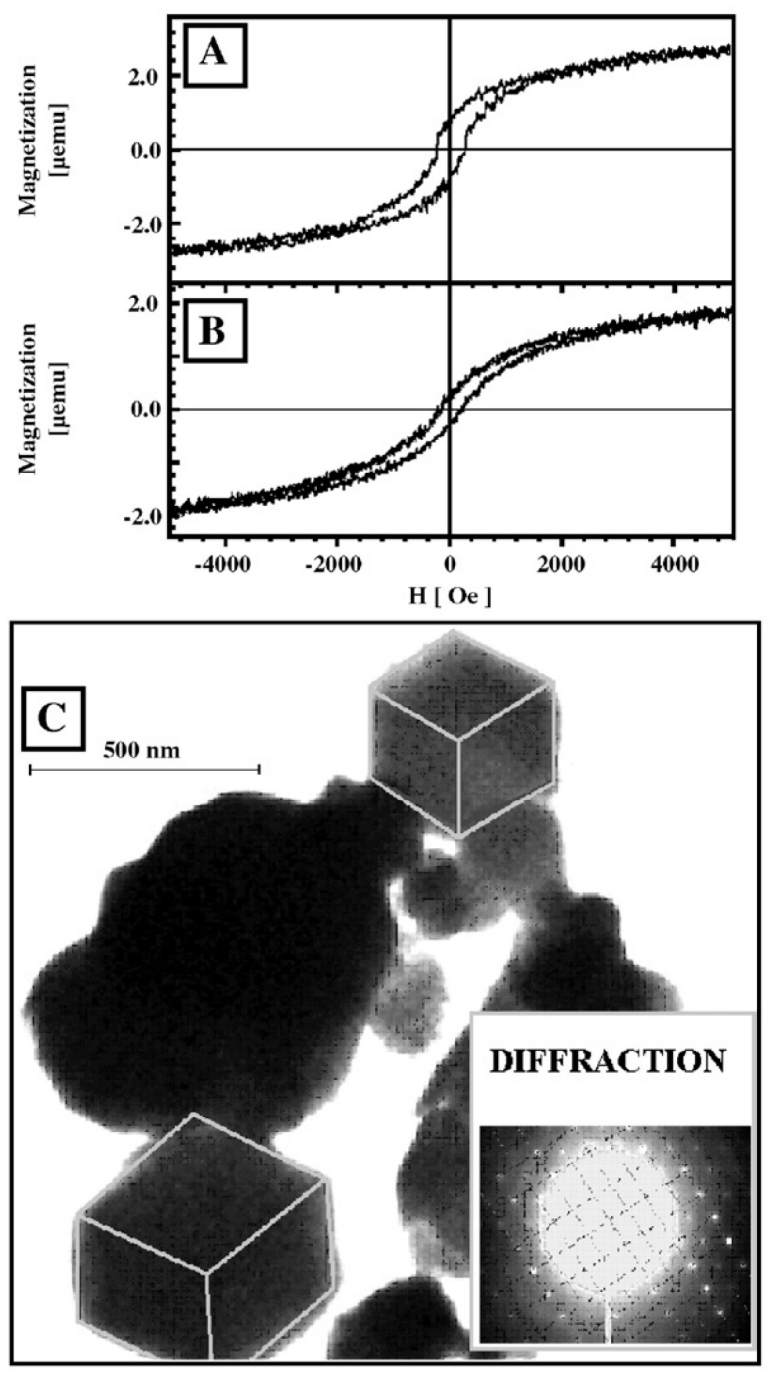

Figure 2. Hysteresis loops for (A) parallel and (B) perpendicular orientation of the external field relative to the film plane. C. TEM spectrum of PPY-Fe nanocomposites. The cubic $\alpha$ Fe blocks are shown. Electron diffraction is shown in the inset. 
silver lines are shown. The amplitudes and positions of WAXS lines were analyzed using JCPDS powder diffraction data available from the International Center for Diffraction Data. A good correlation between WAXS pattern and the JCPDS data was found for cubic iron (lattice parameter ranging between 2.853 and $2.886 \AA$ ). The absence of the line located at $2 \theta=49^{\circ} 46^{\prime}$ (reflection [102], intensity 100\%) rules out the presence of hexagonal iron. The absence of the lines located at $2 \theta=30^{\circ} 30^{\prime}$ (reflection [206], intensity $34 \%$ ) and at $2 \theta=57^{\circ} 5^{\prime}$ (reflection [1 115 ], intensity $34 \%$ or reflection [511] intensity 33\%) rules out the presence of maghemite $\left(\gamma \mathrm{Fe}_{2} \mathrm{O}_{3}\right)$. The absence of the line located at $2 \theta=35^{\circ} 5^{\prime}$ (reflection [311], intensity 100\%) and of the line located at $2 \theta=53^{\circ} 6^{\prime}$ (reflection [422], intensity $10 \%)$ rules out the presence of magnetite $\left(\mathrm{Fe}_{3} \mathrm{O}_{4}\right)$. The absence of the lines located at $2 \theta=106^{\circ} 8^{\prime}$ (reflection [420], intensity $100 \%$ ) and $2 \theta=103^{\circ} 7^{\prime}$ (reflection [331], intensity $60 \%$ ) rules out the presence of wuestite $(\mathrm{FeO})$. The absence of the lines located at $2 \theta=27^{\circ}$ and $35^{\circ}$ rules out the presence of akaganeite. The presence of hematite is ruled out by the absence of any diffraction line in the range $50^{\circ}$ to $60^{\circ}(2 \theta)$. The diffractogram shown in Figure 1B suggests the presence of cubic iron. Iron has several cubic structures. The alpha iron is a stable phase with a body center cubic structure and magnetic properties. Beta iron is not magnetic and its presence was ruled out based on magnetic measurements. Gamma iron has a cubic with faced centered symmetry. Stable phases above room temperature with

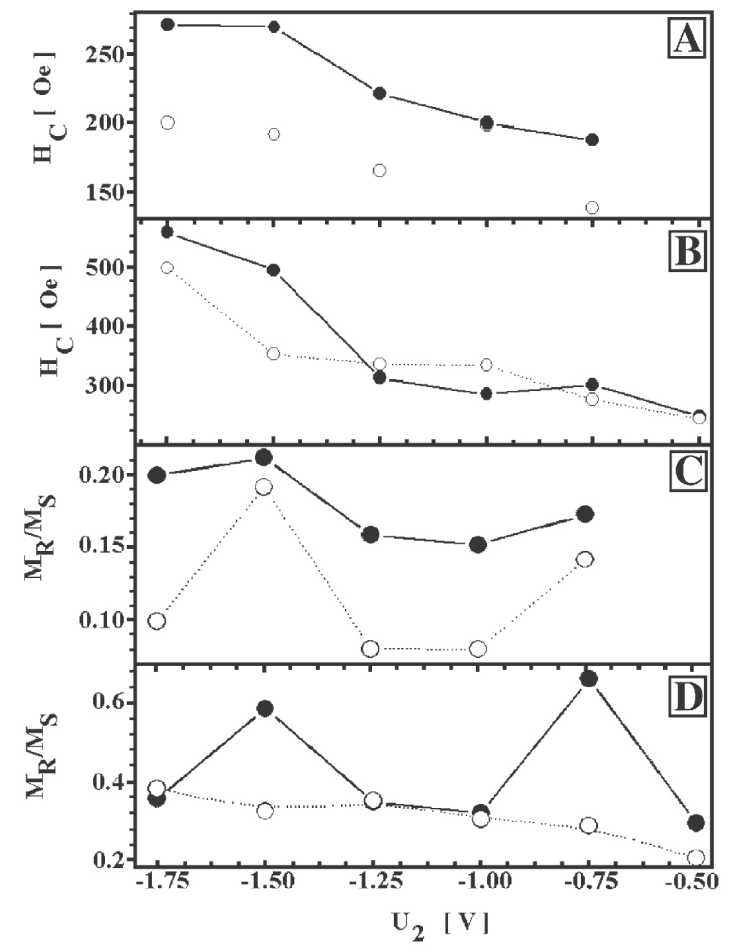

Figure 3. The dependence of the coercive field, for the parallel $(\bullet)$ and perpendicular (०) configurations, on the amplitude of the iron electrodeposition voltage $\left(U_{2}\right)$ : (A) PPY-Fe nanocomposites doped with $\mathrm{LiClO}_{4}$ and undoped PPY-Fe nanocomposite (B). The dependence of the hysteresis loop's squareness, for the parallel $(\bullet)$ and perpendicular $(\circ)$ configurations, on the amplitude of the Fe electrodeposition voltage $\left(U_{2}\right) .(\mathrm{C})$ PPY-Fe nanocomposites doped with $\mathrm{LiClO}_{4}$ and (D) undoped PPY-Fe nanocomposite. ferromagnetic order have been recently reported in gamma iron [14] and [15]. However, the lattice constant for gamma iron is larger than $3 \AA$ [15]. Hence; the wide angle X-ray scattering (WAXS) data indicates the presence of alpha iron in polypyrrole-Fe nanocomposites. Recent investigations [16] on $\alpha$ Fe nanoparticles revealed the presence of a strong diffraction peak, characteristic to [ 1110$]$ reflections, which is absent in our case. This may indicate either a preferential orientation (texture) of Fe clusters or a distorted structure.

The AGFM hysteresis loops of PPY-Fe nanocomposite, obtained using $\mathrm{LiClO}_{4}$ as dopant at an electrodeposition potential of $1.0 \mathrm{~V}$ for PPY and -1.25 for $\mathrm{Fe}$, in the parallel and perpendicular configuration, are shown in Figure 2A. From Figure $3 \mathrm{~A}-\mathrm{B}$ it is observed that the coercive fields are ranging from 100 Oe $(0.01 \mathrm{~T})$ to about 600 Oe. These coercivities are larger by an order of magnitude than the coercivities of the nanocomposite consisting of iron oxide and polypyrrole [6]. However, such values for the coercivity of $\alpha$ Fe nanoparticles were reported elsewhere [16] and [17], supporting the X-ray diffraction data. As it is shown in Figure $3 \mathrm{~A}-\mathrm{B}$, the coercive field in both parallel and perpendicular orientations is enhanced as the applied voltage $\left(U_{2}\right)$ is increased. This may be due to the fact that at low voltages the Fe particles are very fine (close to the superparamagnetic behavior). The increase of the applied potential will increase the amount of Fe deposited during the negative pulse, leading to larger particles. At low Fe electrodeposition potentials, the difference between the coercivities in the parallel and perpendicular configuration is small. Increasing the applied voltage the anisotropy is enhanced. This suggests that at low applied voltages the iron is deposited in clusters. Increasing the applied voltage the amount of iron deposited in each cycle is enhanced, and the clusters coalesce, tending to form a thin layer, enhancing the role of shape anisotropy (see Figure 1B). The difference between the coercive field in the parallel and perpendicular orientations reflects the combined effect of shape and magnetocrystalline anisotropy. As it is observed from Figure 3A-B, the coercive field is higher if the magnetic field is parallel with the surface of the sample. For elongated $\alpha$ Fe such a case has been reported in elongated particles if the easy avis is assumed to be along the long axis of the particle (or particle cluster) [17]. Hence, magnetic data confirmed a textured structure of $\alpha$ Fe within the nanocomposite.

The presence of $\mathrm{LiClO}_{4}$ leads to higher coercive fields due to an acceleration of the overall electrodeposition rate. The anisotropy in the coercivity for the sample electrodeposited with $\mathrm{LiClO}_{4}$ is smaller than in the case in which the doping agent is absent.

The squareness of the hysteresis loops is defined by the ratio between the remnant magnetization, $M_{R^{\prime}}$ and the magnetization at saturation $M_{\mathrm{S}}$. It characterizes the shape of the hysteresis loop. A perfect hysteresis loop has a squareness of 1 . The squareness of the hysteresis loop has a complex dependence of the Fe electrodeposition potential. Figure 3C-D shows that the squareness has an increasing trend as the applied voltage is increased and that the squareness for the perpendicular configuration is higher than the squareness for the parallel one.

The maximum size of the Fe particles (estimated from the overall magnetization at saturation of the nanocomposite $M_{\mathrm{S}^{\prime}}$ taking into account that the saturation magnetization of bulk iron is $1710 \mathrm{emu} / \mathrm{g}$, assuming that a single aggregate is deposited during an electrodeposition pulse, and that the magnetization at saturation is not affected by the size of these aggre- 
gates) is about $100 \mathrm{~nm}$. The TEM micrograph shown in Figure $2 \mathrm{C}$ confirms these estimations. The electron diffraction (Figure 2C; inset) proves that the magnetic particles are crystallized. The poor mechanical properties of this nanocomposite prevented us from measuring the electrical conductivity of PPYFe nanocomposites.

\section{Conclusions}

A new method to prepare nanocomposite materials that combines electrical and magnetic properties is described. Their structure and magnetic properties have been confirmed by FTIR, WAXS, TEM, and AGFM measurements. It was shown that the electrodeposition parameters may be used to tune the magnetic properties of these nanocomposites. Such materials may exhibit negative index of refraction features if the plasma and magnetic resonances are matched. Further studies on polypyrrole-iron nanocomposite properties and their eventual applications are in course.

\section{Acknowledgment}

This research was supported by NSF-MRSEC, NRI and CMRA.

\section{References}

1. J. Xiao, J.U. Otaigbe, and D.C. Jiles, J. Magn. Magn. Mater. 218 (2000), p. 60.

2. A.T. Pomonarenko, V. Shevchenko, C. Klason, and A.I. Pristupa, Smart Mater. Struct. 3 (1994), p. 409.
3. B.H. Sohn, R.E. Cohen, and C.C. Papaefthymiou, J. Magn. Magn. Mater. 216 (1998), p. 182.

4. G. Cik, F. Sersen, and L. Dlhan, J. Magn. Magn. Mater. 218 (2000), p. 78.

5. A.E. Varfolomeev, D.Yu. Godovskii, G.A. Kapustin, A.V. Volkov, and M.A. Moskvina, JETP Lett. 67 (1998), p. 39.

6. J. Liu and M. Wan, J. Polym. Sci. 38 (2000), p. 2734.

7. R. Singh, A.K. Narula, R.P. Tendon, A. Masingh, and S. Chandra, J. Appl. Phys. 80 (1996), p. 985.

8. G.J. Cruz, J. Morales, and R. Olayo, Thin Solid Films 119 (1999), p. 342.

9. R. Kostlic, D. Rakovic, S.A. Stepanian, I.E. Davidova, and L.A. Gribov, J. Chem. Phys. 102 (1995), p. 3104.

10. R. Turcu, M. Brie, G. Leising, V. Tosa, A. Mihut, A. Niko, and A. Bot, Appl. Phys., A 67 (1998), p. 283.

11. R.S. Kohlman, J. Joo, Y.Z. Wang, J.P. Pouget, H. Kaneko, T. Ishiguro, and A.J. Epstein, J. Phys. Rev. Lett. 74 (1995), p. 773.

12. G. Zerbi, M. Veronelli, S. Martina, A.D. Scluter, and G. Wegner, J. Chem. Phys. 100 (1994), p. 978.

13. K.S. Rane, V.M.S. Verenkar, and P.Y. Sawant, Bull. Mater. Sci. 24 (2001), p. 331.

14. F.J. Pinski, J. Staunton, B.L. Gyorffy, D.D. Johnson, and G.M. Stocks, Phys. Rev. Lett. 56 (1986), p. 2096.

15. P. Ehrhart, B. Schonfeld, H.H. Hetwig, and W. Pepperhoff, J. Magn. Magn. Mater. 22 (1980), p. 79.

16. Y.J. Chena, M.S. Cao, Q. Tian, T.H. Wang, and J. Zhu, Mater. Lett. 58 (2004), p. 1481.

17. J. Yu, U. Rudiger, A.D. Kent, L. Thomas, and S.S.P. Parkin, Phys. Rev., B 60 (1999), p. 7352.

18. X.P. Zhao, Q. Zhao, L. Kang, J. Song, and Q.H. Fu, Phys. Lett., A 346 (2005), p. 87. 